\title{
Enhancing the recruitment of postgraduate researchers from diverse countries: managing the application process
}

\author{
Kyung Hye $\mathrm{Kim}^{1}$ (D) Helen Spencer-Oatey ${ }^{2}$ (D)
}

Accepted: 8 January 2021 / Published online: 21 April 2021

(c) The Author(s), under exclusive licence to Springer Nature B.V. part of Springer Nature 2021

\begin{abstract}
International students form an important element of most universities' internationalisation strategies, especially for research and the recruitment of high calibre $\mathrm{PhD}$ students (PGRs). Despite the numerous studies of PGRs' post-arrival experiences, there is a major dearth of research into their pre-arrival, application experiences. Given the worldwide competition for high calibre PGRs, along with impact posed by the Covid-19 pandemic and by Brexit for the UK, it is vital for universities to ensure that factors clearly under their control, such as the information on their websites and the way they communicate, are as informative and helpful as possible. In this article, we draw on social media data to examine the challenges and uncertainties that Korean PGR applicants experienced in navigating the process of applying to UK universities. The paper compares their confusions with information available on university websites and recommends a series of points that higher education institutions should check for. It also reveals and discusses issues associated with communication. While the data has been collected from Korean social media websites, we argue that our paper has broader relevance for the following reasons. First, the same fundamental intercultural issues - different educational systems and different background knowledgeapply to PGR applicants from other countries and so their queries are likely to be similar or comparable. Second, the insights gained from social media websites to facilitate the application process and thereby enhance recruitment can usefully be applied to other countries and levels of study, in a way that has rarely been done to date.
\end{abstract}

Keywords Application process $\cdot$ Recruitment $\cdot$ Higher education $\cdot$ International research students · Uncertainties · Korean

Kyung Hye Kim

kyunghye.kim@sjtu.edu.cn

Helen Spencer-Oatey

Helen.Spencer-Oatey@ warwick.ac.uk

1 Shanghai Jiao Tong University, Shanghai, China

2 University of Warwick, Coventry, UK 


\section{Introduction}

The number of international students around the world has expanded rapidly in recent years. The OECD B6 indicator (OECD, 2018) shows that over the past two decades, the number of foreign enrolments in tertiary education worldwide has exploded from 2 million in 1998 to 5 million in 2016 for students from non-OECD countries, and from 1.5 million in 1998 to 3.5 million in 2016 for those from OECD countries. Moreover, it states that the more advanced the level of education, the higher the proportion of international students. The report points out that while international students account for only $6 \%$ of total enrolment in tertiary education, the proportion rises to $26 \%$ for doctoral programmes. On the other hand, the OECD B6 Indicator (OECD, 2018) also reveals that there are noticeable cross-national differences in (a) the inflows of international students from master's to doctoral programmes and (b) the proportion of international students studying for a $\mathrm{PhD}$. This suggests that some countries and/or universities may be better at attracting high calibre international PGRs than others.

In the UK there is a national strategic imperative to recruit more PGRs. The UK Council for Graduate Education (UKCGE, 2020) reports that there needs to be a $10.16 \%$ rise in postgraduate research enrolments, if the 2027 target of the government's R\&D Industrial Strategy is to be met. However, as can be seen from Fig. 1, the trend over recent years is not encouraging. In fact, the UKCGE policy paper argues as follows:

These trends in postgraduate research enrolments show that a $10.16 \%$ growth by 2027 will not happen by itself. The Industrial Strategy will depend on the strategic development of the postgraduate researcher pipeline.

Mellors-Bourne et al. (2014) report that although nearly all the UK universities in their study were seeking to increase their PGR numbers, they had no clear strategies for achieving this.

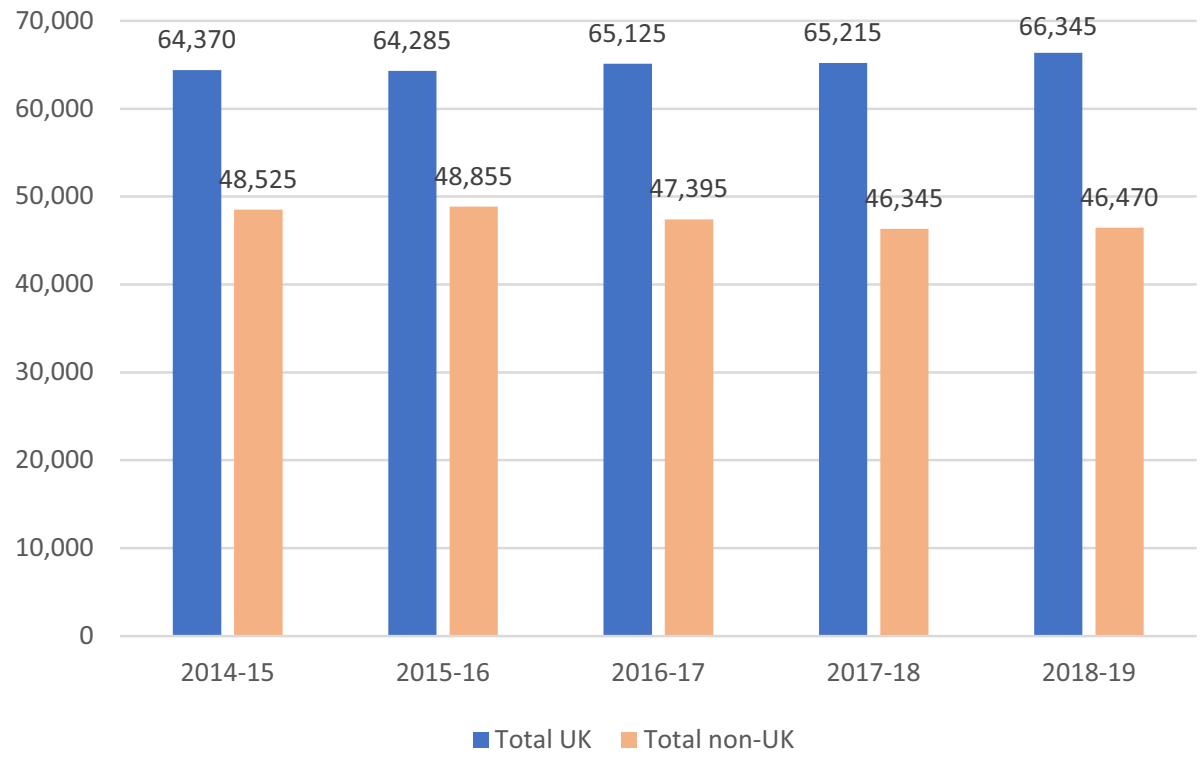

Fig. 1 PGR Enrolments in the UK (derived from HESA data, 2020, https://www.hesa.ac.uk/data-and-analy sis/students/where-from) 
Almost all institutions are currently seeking at least some growth in their PGR numbers, although this is frequently not translated into formal quantitative targets. Growth is especially sought in international PGRs, although strategies for achieving it were not always clear, other than expressing an aspiration for the best possible talent. (p. 2)

This is concerning. Several institutions mentioned that there was strong competition for the most highly-qualified PGRs and that they often lost out to quicker and more competitive offers from the USA and Canada. Almost one third expected a decrease in demand from international PGRs, partly because of the increase in the number of universities in other countries offering attractive provision in English, and partly due to the reduction in attractiveness of the UK as a study location because of immigration policies. This is clearly in tension with their desire for higher numbers of PGRs.

Attracting more PGRs is likely to be exacerbated by both Brexit and Covid-19. It is extremely important, therefore, that the higher education sector considers ways of attracting a higher proportion of the international $\mathrm{PhD}$ student market, while retaining quality. One facet of this is the application experiences of potential applicants, and this is the focus of our article. If universities in (some) other countries are able to make faster offers, as Mellors-Bourne et al. (2014) report, then it is important to gain more insights into the application process and the challenges that international students may experience with the British system.

In this paper, we take a country case study approach and use social media data to examine the challenges that Korean PGR applicants experienced in navigating the process of applying to UK higher education institutions (HEIs).

$\mathrm{PhD}$ places in Korean universities are not particularly competitive, and the number of $\mathrm{PhD}$ graduates from Korean universities has increased steadily from 12,625 in 2013 to 15,308 in 2019 (Statistics Korea, 2020). However, both universities and companies in Korea prefer to recruit doctoral candidates who have graduated from overseas universities (Cheong \& Song, 2010; Kim, 2020). As a result, those students who want a career in academia or a specialised job in industry are particularly keen to study abroad. These students have clear aims, are committed, and are likely to come back to Korea. They thus offer good opportunities for building research collaborations between their Korean employer and their UK university of study, and thereby help support the UK government's R\&D Industrial Strategy.

Despite our focus on Korea, we argue (as we explain further below) that the relevance of our study is not limited to Korean applicants, nor necessarily to UK HEIs, since many of the uncertainties that the applicants asked about are likely to be similar for other international students, especially those from Asia. We start by reviewing the literature on the (PGR) application process, looking first at HEI perspectives and then at student experiences. As Mellors-Bourne et al. (2014) point out, 'the published evidence base relating specifically to the attraction, recruitment and selection, and deployment of PGRs is limited'.

\section{HEI accounts of the PGR application process}

The only substantial research into the PGR application process from the perspective of HEIs is that of Mellors-Bourne et al. (2014). One of the first things these authors point out (p. 3) is that the recruitment and selection process are complex and varied. This variation extends to the decision-making process and the individuals involved, including the 
roles played by the potential supervisor, departmental academic panel, senior research academic, research degrees committee, and central admissions. Often multiple people/ units are involved, but there is variation both across and within universities, including by department and discipline, in their exact roles, power, and influence. In terms of the selection steps, interviews may or may not take place. They more often involve the potential supervisor than an academic panel, but they tend to vary in degree of formality as well as frequency. Mellors-Bourne et al. (2014) report that the final decision is rarely with the potential supervisor, but that there is often a well-known hierarchical chain of approval following a departmental recommendation.

Almost all institutions that participated in Mellors-Bourne et al. (2014) study said they would need to have a certain amount of interaction with potential applicants prior to any decision. Most said they would need to spend time explaining the application process, and many (but not all) reported having prior discussions about the research topic. How much feedback was given on a draft research proposal was much more varied, though. The authors argue that given the complex and individual nature of the PGR application process, building a positive initial relationship with a potential supervisor is highly advantageous. However, this in itself can risk issues of fairness. There was an indication that internal candidates would be more likely to receive feedback and support over the whole application process than external candidates, raising potentially serious questions of equity of access, especially for international students. The authors suggest that one way of addressing this problem could be to have pre-application workshops, and they describe one particular university where this had been introduced and seemed to be working well.

Mellors-Bourne et al. (2014) collected a small amount of data from PGR students, and these also pointed to significant differences between the experiences of internal and external applicants, including problems of transparency faced by the latter. As a result, two of their recommendations to HEIs and policy makers are on gathering information from PGR applicants and students themselves. They recommend collecting data from current or recent PGRs on their experiences, 'especially application and recruitment processes' (p. 60) and adding some additional questions to the Postgraduate Research Experience Survey (PRES) on application experiences.

We turn now to the experiences and viewpoints of international PGR students.

\section{The application experiences of international PGR students}

There have been numerous studies of the experiences of international students in higher education, including issues of integration (e.g. Spencer-Oatey \& Dauber 2019a, b), effective group work (e.g. Montgomery, 2009; Spencer-Oatey \& Dauber, 2017), expectations around teaching and learning (e.g. Cortazzi \& Jin, 2002), and classroom participation (e.g. Zhou et al., 2005). However, none of these studies focus on PGR students and they all address issues that students face after the commencement of their studies. Yet, as reported in the previous section, it is quite possible or even likely that prospective students come up against issues during the application stage, and when this happens, both applicants and the UK HEIs may potentially lose out. The applicant may decide to go elsewhere (to a country or institution where the application process is clearer), and staff involved in handling applications (both academic and professional services staff) may spend time responding to queries that 
could otherwise be reduced. Such concerns were found by Mellors-Bourne et al. (2014), as reported above.

Despite the recommendation by Mellors-Bourne and his colleagues for some questions to be added to the PRES survey, the 2019 version had no additional questions on application experiences. On the other hand, a report by Archer (2016), using PGR data from i-graduate's International Student Barometer, ${ }^{1}$ identifies a section with questions on 'application and decision-making'. Unfortunately, however, he does not include any account of them in the report. Nevertheless, he makes two relevant recommendations:

\section{Recommendation 9}

Given the intensely competitive environment, universities should establish strategies to ensure applications are processed expeditiously and that offers made to students are tracked in order to maximise conversation rates through to enrolment.

\section{Recommendation 10}

Universities, sector bodies and Government should consider a more substantive process for collecting and collating evidence of the decision making, influences and routes to postgraduate research study in the UK.

(Archer, 2016, p. 8)

In other words, he draws attention to the importance of monitoring and expediting the PGR application process.

Quacquarelli Symonds (QS) also include some relevant questions in their 'International Student Survey' (Berka \& Strods, 2020). Some questions probed viewpoints on communication during the PGR application process and especially in relation to timing and frequency:

- When communicating with a university about an enquiry or application, the importance of not having to wait very long to hear back

- How often would you expect a university to contact you after you apply?

- How often would you expect a university to contact you after you receive an offer?

Unsurprisingly, most Asian PGR respondents (as well as the sample as a whole) felt it was very important (33\%) or fairly important $(60 \%)$ to hear back soon. Much more surprising, though, was that about a quarter of them felt it was important for the university to contact them daily, both after application and after receiving an offer, and more than half of them felt it needed to be weekly, making an amazing $75 \%$ or more wanting frequent or extremely frequent communication.

Other questions in the survey concerned sources of information and pre-arrival contact with the university. Two of these questions were as follows:

- Who do you think is best equipped to provide application information?

- Who do you think is best equipped to provide information on fees and scholarships?

\footnotetext{
${ }^{1}$ https://www.i-graduate.org/international-student-barometer
} 
Respondents had three choices: a current student, university staff, someone else. Not surprisingly $76 \%$ of their Asian sample chose university staff. Another question listed a large number of potentially useful information sources for researching a university and asked respondents to select the five most useful to them. The results indicate that university websites, general online search, and university rankings are the most important sources to PGR respondents irrespective of region/nationality. After that, preferred sources that were selected by around one quarter or more of Asian respondents include course finder websites, institution information sessions, social media channels, printed university prospectus, and online forums/chat rooms.

In line with this, it would seem completely understandable that when digitally savvy and academically competent students have not been able to find the information they desire from their top preferred sources, they will turn to online channels and social networking sites. Previous studies (e.g. Royo-Vela \& Hünermund, 2016; Galan et al., 2015) have shown that for those who do not apply through agents, online channels have a significant impact on postgraduate students' decision-making processes. However, as Gai et al. $(2016,182)$ rightly note, previous studies on student recruitment at HEIs almost exclusively use interviews and surveys, overlooking the fact that the whole application procedure involves students carrying out extensive information searches online and a complicated decision making process (Mowen \& Minor, 2006; Gai et al., 2016, 189). The HE context has also been 'slower in recognising the value of student-generated social media data and content for HE marketing, branding and recruitment purposes' (Bolat \& O'Sullivan, 2017, 745).

An exception to this is Gai et al. (2016). They examined the stages of the international student consumers' decision-making process by looking at extensive authentic data generated and posted by prospective students on ChaseDream.com (an interactive online virtual community for Chinese-speaking students), focusing on the application process for a Business MA degree in the USA. Building on previous work by Galan et al. $(2015,292)$, who identified four stages of a decision-making journey involving social media (problem recognition, information search, evaluation of alternatives, and purchase decision), Gai et al. $(2016,190)$ propose a set of five stages: predisposition, information seeking for targeting schools, application, evaluating admission offers, and final decision. They report that during the application stage, 'users read previous CDer's [ChineseDeam user] testimonials while preparing for school/program interviews' (p. 190). This clearly attests to the crucial role that students' online comments play in the application decision-making process.

However, these authors did not analyse the nature and the type of the queries posted in their own right; nor did they focus on PGR students. So, in order to help complement the limited research data available on the PGR application process, we decided to explore the following research questions:

RQ1: What information is unclear to applicants?

RQ2: What challenges do PGR candidates experience during the application process?

RQ3: What PGR application information is available on UK national and university websites?

RQ3 was included so that we could make a contextual interpretation of the findings from RQ1 and RQ2, allowing us to compare what students were asking about with what information was or was not already available or clear. 


\section{Methodology}

For RQ1 and RQ2 we collected data from two interactive online forums. South Korea has a particularly vibrant web culture - according to Statistica (2020), the percentage of the population using the internet has continuously grown since $2000(44.7 \%)$, and it reached $95.9 \%$ by 2018 . Korea topped (in 2008, 2010, 2011, 2012, 2015, 2016) or ranked second $(2013,2014,2017)$ on the list of top thirty countries ranked by the ICT Development Index (IDI), an index published by the United Nations International Telecommunication Union. ${ }^{2}$ Thus, it is not surprising that there are numerous online communities, forums, as well as personal blogs, including those for Korean students seeking help and advice for studying abroad and which allow dynamic interaction. Nevertheless, these online data have rarely been used previously for analysis, although they reveal fascinating insights into the genuine issues and uncertainties that students are facing. These online communities and forums allow users to pro-actively gather relevant background information about the application process, while also retaining anonymity in the cyberspace, thus allowing more open communication.

Questions and comments shared by prospective Korean students in two Korean online forums - '영국사랑' (www.04uk.com, hereafter 04UK) and '고우해커스' (www. gohackers.com, hereafter $\mathrm{GOH}$ )—were retrieved. These online communities and forums were chosen mainly because they are the platforms that allow users to interact and exchange questions and comments relating to the UK, including issues of living and studying in the UK. At the time of writing, 04UK features a section '대학 (원)' [u/g and p/g] under the 'Q\&A' section. $\mathrm{GOH}$ is a platform provided and operated by Hackers Language Institute Co., Ltd. As one of the biggest language institutes providing foreign language education in South Korea, it features more specific categories than 04UK, including a '영국유학 Q\&A' [Q\&A about studying in the UK] section. These two sites contain rich archives of authentic communication and interactions, enabling us to investigate the real struggles that prospective Korean students have faced in terms of their UK application process.

At the time of data collection (16 December 2018), 04UK (which started from October 2010) featured a total of 2797 postings, while GOH (which started January 2006) featured 23,481 . In order to obtain only the postings concerning the $\mathrm{PhD}$ application process that require some understanding of the UKHE system, postings were narrowed down first by using the search words '교수 [professor/lecturer/senior lecturer/reader]', '지도교수 [supervisor]', '튜터 [tutor]', and '렉처러 [lecturer]'. These key words separated the postings that require communication with potential academic staff on the one hand, and on the other, they also allowed us to exclude the questions that could be easily answered by information available on institutions' websites. Using 'application' as the search word would have introduced an unnecessary level of noise. For example, it will also return questions such as 'what does 'academic references' on the application mean?', 'somehow I failed to upload the files onto the system', and 'May I submit the application now but references later?'. The selected postings were then further refined by excluding those that did not relate to application issues in the UK, e.g., questions about ways to get a reference letter from a Korean academic, as part of the application process required by a UK institution. All these processes resulted in 431 postings for 04UK and 1702 for GOH. No log-in process is required for these two websites for reading, and users can use alias.

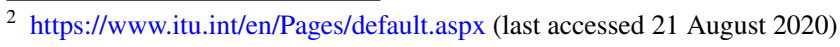


The questions were then manually imported into MAXQDA, a software package widely used for qualitative data analysis, so that the comments could be coded and analysed systematically. The comments were translated into English by the first author, before they were imported into the analysis software programme, but both Korean and English wordings were retained in the imported documents to help ensure that no meanings had been lost or slightly altered during the translation process. Both authors then participated in the analysis, first reading through each of the entries several times to familiarise themselves with the data. After this, multiple iterations of conventional content analysis (Hsieh \& Shannon, 2005) were carried out. In other words, the coding was done inductively, with the coding categories derived directly from the data rather than through the use of a predetermined set of categories. Each full question was treated as the unit of analysis, and since each question often included multiple different elements, each entry (as is normal in qualitative data analysis) could be coded to more than one code. MAXQDA allows the code system to be built with a hierarchical structure, so that there are parent codes, children codes, grandchildren codes, and so on.

For RQ3 we examined the information on the application process available from the five UK universities who have the largest number of Korean PhD students (see Fig. 2). The institutions mentioned in the student queries could also in principle have been examined, but the names of institutions were not usually mentioned. Moreover, the aim of this study is not to offer tailor made suggestions to specific institutions but rather to (a) identify types of challenges Korean applicants experience in navigating the process of applying to UK HEIs and (b) make recommendations that can be applied across different institutions.

At each institution's website, 'Application' or 'postgraduate research programme' pages (not a specific study or department) which offer current general application practices and information were examined. This is because each study/department may offer subtly different level of specific application information, and it is impractical to review it within the scope of this article. Each university has its respective YouTube channel, so their channels were checked as well. Although they present some videos about application processes, none were found to focus specifically on $\mathrm{PhD}$ student applications. Our analysis will thus be on the website information. In analysing these various data sources, we focus on the application challenges of prospective PGRs, which had a particularly high number of codings (for a different focus - challenges in relating to UK academics - please see Kim and Spencer-Oatey, 2020). This main theme had four main sub-themes: application steps, communication uncertainties, financial queries, and English language proficiency issues (see Fig. 3). For space reasons, we focus here on the first three sub-themes.

Fig. 2 The five universities in the UK with the largest number of Korean PhD students (The Korean Education Centre UK, 2019)

\begin{tabular}{clc}
\hline & Name of the University & PhD \\
\hline $\mathbf{1}$ & University College London & 45 \\
\hline $\mathbf{2}$ & The University of Oxford & 35 \\
\hline $\mathbf{3}$ & The University of Cambridge & 25 \\
\hline $\mathbf{4}$ & The University of Manchester & 15 \\
\hline $\mathbf{5}$ & $\begin{array}{l}\text { Imperial College of Science, Technology and } \\
\end{array}$ & Medicine
\end{tabular}




\section{Findings}

This section reports on the three most frequently queried sub-themes and compares them with the information provided on key university websites.

\section{Issue 1: Application steps-Social media findings}

By far the largest number of questions concerned the steps involved in the application process. There were 114 such questions, covering a range of issues, as shown in Fig. 4.

Application paperwork (23 codings) refers to questions about the content of the necessary application paperwork, particularly about the nature of the research proposal and queries about references. In other words, applicants were uncertain about how to write or prepare the documentation required by the university.

Another issue of concern was sequencing and timing. Applicants were unsure whether they should contact a potential supervisor prior to application or just apply directly. There were 23 codings on this issue, indicating a fair amount of concern among the potential applicants. Students became particularly concerned when there was a time delay in hearing back, leading them to wonder whether they had followed the right procedure or not. Others had a variety of questions about timing-how long it takes to get an offer/decision or even a response. For instance, one person had been waiting 6 weeks for a formal offer, when their future supervisor had said it would take about 3 weeks from his unofficial offer. This length of time contrasts strongly with the expectations revealed in the QS survey data reported above.

A third main set of codes related to uncertainties over the decision-making process. This received the largest number of questions relating to application steps. There were 32 codings to this category, indicating that there is quite widespread confusion over this issue. The uncertainty mentioned most frequently (16 codings) was responsibilities for decisionmaking, especially the relative power of the supervisory professor and the admissions office in the process (e.g. Q1 and Q2).

Q.1 I wonder if the potential supervisor agrees, the admission office would offer me an acceptance letter. Or do you think the admission office would reject my application even when the potential supervisor agreed? [GOH56, Code AS-DM-DMR] Q.2 Is there any case where a $\mathrm{PhD}$ application is rejected even when a professor showed a positive response? [GOH56, Code AS-DM-DMR]

Fig. 3 Screenshot of the main code categories of 'Application Challenges' and their coding frequencies (collapsed view)

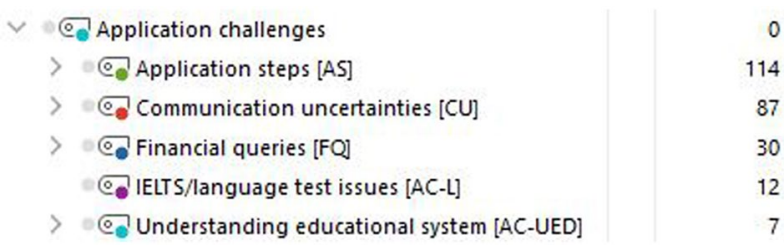


Fig. 4 Screenshot of the main code 'Application Steps', with sub-themes and coding frequencies (uncollapsed view)

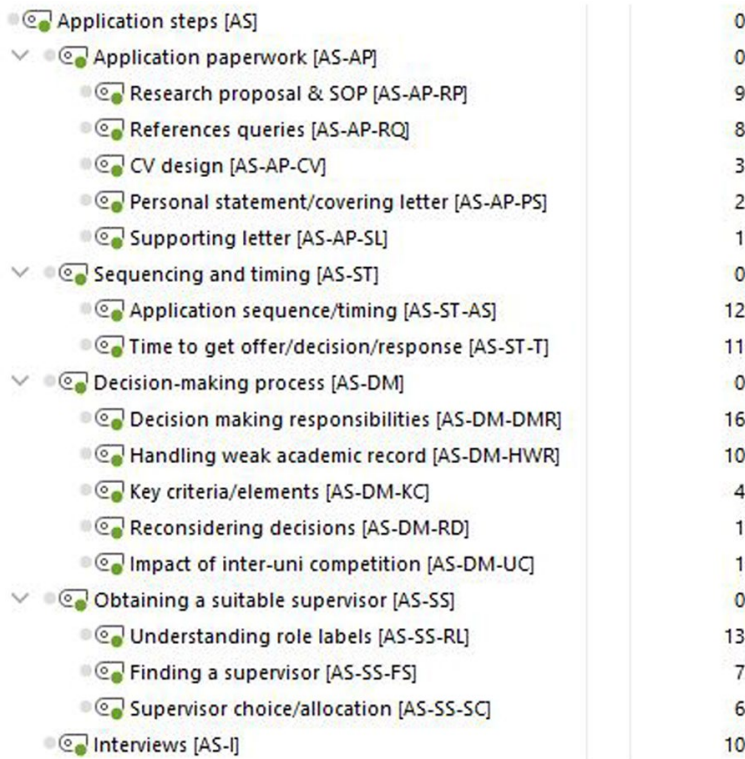

The second most frequent uncertainty over decision-making (10 codings) concerned ways of handling a weak academic record. Sometimes this was interlinked with uncertainty over decision-making responsibilities, as indicated in the next quote (e.g. Q3).

Q.3 I had an interview with my professor in person 10 days ago. Everything went fine, and the professor said there would be no problem in getting the acceptance. However, I'm worried because my GPA is low. The professor said it would be covered by my three years' experience in $\mathrm{R} \& \mathrm{D}$, and some projects I was involved in, and because my research plan was impressive. I wonder if the supervisor has more power over the admission decision. Or, do other professors in the department also have to agree to the $\mathrm{PhD}$ candidate? [GOH224, Code AS-DM-HWR].

A few students had other decision-making queries, such as what key criteria an admission committee uses and whether a rejection decision can be reconsidered.

A fourth important group of questions relating to application steps concerned identifying a suitable supervisor (26 codings). Some of this stemmed from confusion over role labels and who was eligible to supervise $\mathrm{PhD}$ students (e.g. Q4).

Q.4 The university website shows Lecturer, Reader, and Professor under the Academic Staff. I wonder if they can all be PhD supervisors, or if only Professors can be the supervisors. [GOH66, Code AS-SS-RL]

This confusion, of course, affects students' ease of identifying potential supervisors. Sometimes students asked about other aspects of finding a supervisor, such as whether a Korean academic would be willing to take a Korean $\mathrm{PhD}$ student and whether to trust a professor who is not willing/able to provide any funding.

The fifth group of questions relating to application steps concerned interviews (10 codings). Some had been invited to an interview and wondered who would conduct the interview, what questions would be asked, and so on. Others, who had not been invited for 
interview, wondered whether not being invited was problematic as they had heard of others being interviewed.

\section{Issue 1: Application steps-Website information}

Among the five universities in Fig. 2, three provide a decision timeline or flow chart describing the application process, while the other two only provide a list of required documents and a general description of the procedure and right of appeal. In addition to a decision timeline, the University of Oxford describes six clear steps in their application guideline.

Few of the universities explicitly mention who is in charge of the application process. The University of Cambridge is one of the few who does, stating that the departmental faculty will consider the application first, before the application is approved by a degree committee and Graduate Admissions Office on behalf of the Board of Graduate Studies. This statement at least delivers a message to potential applicants that the admission process is beyond the control of individual academic staff. Other universities mention 'our admissions selectors' or 'Graduate Admissions office' as the body who will process the applications, but applicants may assume faculty members are part of the 'selectors', and none of the other four provide such explicit information as that of The University of Cambridge.

Some universities mention the possibility of re-evaluation of the submitted application, a potential waiting list, and a process for complaints. All universities in Fig. 3 quite clearly encourage applicants to identify an appropriate supervisor and to send an informal research enquiry either directly to the academic or the departmental contact prior to submitting the application. However, none of the five specifically state whether all academics are eligible to supervise PhD students. For example, University College London (UCL) offers a very detailed way to search for a potential supervisor, by stating '[s] earch our online research repository (UCL Discovery) where all UCL's research papers are published, subject to approvals. If you identify a research paper that particularly interests you, it is likely that one of the authors would be a suitable research supervisor'. However, often an online research repository presents teaching fellows, too, who are in the teaching category. Although this can be checked through personal contact between the applicant and the academic, providing no indication in the general guide page on the supervision eligibility of the academics may cause confusion for international students who are not familiar with the UK HE system.

\section{Issue 2: Communication uncertainties-Social media findings}

The second broad area of concern to students was communication. There were 87 codings to this category, covering three main areas, as shown in Fig. 5: making contact, interpreting responses/guidelines, and wording the content of a message.

There were 38 queries about making contact and, as can be seen from Fig. 5, the two most frequent issues were whether and how often to make contact, and what to do when there was no response or a slow response. In terms of making contact, queries with this coding were not simply about getting accepted (as with Application Steps, Sequencing and Timing). They were asked either before or after acceptance and indicated additional uncertainty over managing the supervisory relationship and research responsibilities (e.g. Q5 and Q6). 
Q.5 I wonder if contacting the professor only twice is enough. It seems others have more frequent communication with a potential supervisor. I wonder what other things you discuss with the professor. [GOH257, Code CU-MC-S]

Q.6 How often do you usually get in touch with your supervisor after receiving an offer, before you leave the country to study in the UK? [GOH138, Code CU-MC-S]

Students became particularly concerned when there was a delay in response and wondering whether they should send a follow-up email. When they did receive a reply, either from the supervisor or from admissions, they sometimes had difficulty interpreting the meaning (e.g. Q7 and Q8). There were 32 queries of this kind.

Q.7 I had an interview with a professor, which went fine. The professor said he was satisfied with the interview, but he thought my academic record might not be recognised and added that I should wait as he'd write a letter to the senior tutors. I do not understand 'your academic record may not be recognised'. What does this mean? [04UK3, Code CU-IR]

Q.8 I sent an email with my CV and SOP attached to a professor to see if s/he could be my $\mathrm{PhD}$ supervisor. Only this strange answer came back. What does this mean? "Thank you for your enquiry. All requests for supervision are via the Doctoral School. Please contact them and they will give you details of the process." [GOH214, Code CU-IR]

In all these cases, the student needed to draw inferences and/or rely on relevant background contextual knowledge (e.g. about the application system and procedures) in order to be able to make sense of the supervisor/university response.

A third but smaller group of queries over communication concerned how to handle awkward situations and what to say. Examples of issues here were how to provisionally accept an offer while expecting to turn it down later, how to politely decline an offer after the potential supervisor has been very helpful, and whether it is impolite to ask a professor about funding opportunities. The latter then brings us to the third main issue: financial queries.

\section{Issue 2: Communication uncertainties-Website information}

Some institutions provide detailed information about ways to contact supervisors prior to submitting applications. The University of Manchester (UoM) and UCL, for example, provide very specific guidelines. UoM even details how to compose an email to a prospective

Fig. 5 Screenshot of the main code 'Communication uncertainties', with sub-themes and coding frequencies (uncollapsed view)

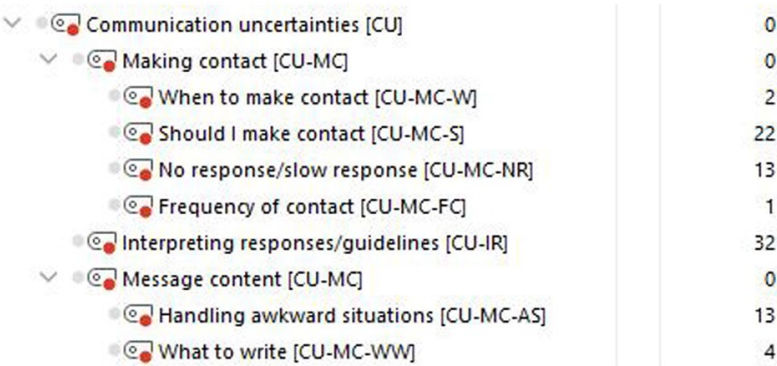


supervisor, and UCL offers detailed guidelines for ways to make a research enquiry, including the amount background needed, as follows:

Academic members of staff are extremely busy people and receive a lot of research enquiries. In a recent survey $67 \%$ of staff said they receive research enquiries that do not relate to their interests. It is extremely important to research supervisor's interests thoroughly before you contact them. If they do not think your enquiry is related to their research they may not have time to respond to you (UCL, Guidance on how to contact potential supervisors).

Such information will certainly help applicants structure their emails to prospective supervisors, and further reduce unnecessary additional email exchange caused by inappropriate email or an email from applicants with insufficient information. It also clearly tells them they may not receive a reply if they have not contacted an appropriate academic.

\section{Issue 3: Financial queries-Social media findings}

A third broad area of concern to students was finance. There were 30 codings on this, covering three main areas, as shown in Figure 6: finding financial support (13 questions), finance and supervisor relations (13 questions), and procedural queries (4 questions).

13 questions focused on obtaining financial support, including the opportunities available (e.g. different scholarship schemes, work opportunities, supervisor's grant), criteria for success, and timings associate with acquiring funding. Another 13 questions asked about relational matters, particularly whether it was appropriate to ask the supervisor about financial issues or whether this would cause offence.

Q.9 I wonder if I also can ask the questions about funding. ... I'm afraid I'll make a bad impression even before I apply. [GOH58, Code FQ-SR-A]

There were four further questions about procedural matters, such as how to complete a funding application form.

Fig. 6 Screenshot of the main code 'Financial queries', with sub-themes and coding frequencies (partially collapsed view)

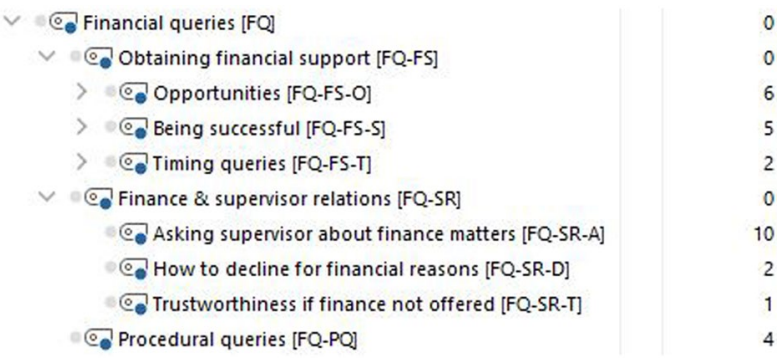




\section{Issue 3: Financial queries-Website information}

As mentioned in Gai et al. (2016, 189), cost is a very important factor for prospective students. All universities provide a significant amount of information about access to financial support. The University of Oxford presents a separate page for their list of studentships by clearly stating the following: '[c]heck your academic department's website for details of any current studentship opportunities and how to apply. There is a section in the online graduate application form where you will be able to enter the code(s), if required, for any studentships for which you wish to be considered'. Imperial College London provides a search tool for all available scholarships and studentships. The University of Manchester, among others, goes further and specifies that candidates can discuss feasible funding opportunities with staff: '[a] good first step in exploring funding options is to speak to staff within your subject area to find out how previous students have financed their studies'. This should make prospective applicants feel comfortable over contacting staff about financial issues before they apply. Nevertheless, information such as this is rarely spelled out in other universities' admission pages.

\section{Discussion and recommendations}

\section{Information provision}

As shown by the findings reported above, the Korean students had a very large number of questions about the various steps involved in applying for a PhD at UK HEIs. Since educational systems are very different, this is completely understandable. The greatest number of questions was about the decision-making process, and especially who has responsibility for what. Of the five UK universities sites examined, only one of them included an explanation of this. Most universities provide information on funding opportunities, but students seem to have questions about more subtle aspects.

As a follow-up study, we looked at four UK national-level websites that provide information on studying in the UK, to check how much information they offered for PGR applicants: UKCISA, Study UK, Steps to Postgraduate Study, and Prospects. Only Prospects provides any information on the PGR application process; others only cover more generic information about studying in the UK, e.g. visa application, and the structure of lectures and seminars. Prospects provide a wealth of information for PGRs on many aspects of the application process, including detailed pages on how to write a research proposal and find a suitable supervisor. One possibility, therefore, would be for universities to include a link to relevant sections on the Prospects webpages. However, this could usefully be supplemented by more specific and local information on universities' own websites. Similarly, each universities' respective official YouTube channels can be linked to the university admission pages (strangely they are not currently), and a series of short videos exclusively focusing on a specific $\mathrm{PhD}$ application issue can be produced. Since the YouTube platform allows

\footnotetext{
3 https://www.ox.ac.uk/admissions/graduate/courses/courses-open-for-studentships?wssl=1 (last accessed 6 July 2020)
} 
viewers to freely leave comments, just like the forums examined in this study, prospective students can ask questions in a more casual environment and receive prompt responses from the university as well as current registered students, while the university can identify issues international students may have with less effort.

We recommend that HEIs review the extent to which they provide information on the following:

1. The expected length of a research proposal.

2. A description of the parties involved (e.g. departmental academic staff and central admissions) in decision-making and what their respective roles are.

3. Criteria for decision-making and the extent to which they are/are not negotiable (e.g. whether a decision made by central admissions can(not) be overridden by other parties, including by the potential supervisor, or vice versa).

4. A timeline or a flow chart that details the whole process, including (a) estimated average time for a decision to be made and (b) sequencing of the various elements (e.g. whether prior contact with a potential supervisor is essential, recommended, or unimportant).

5. The role that interviews play.

6. Explanation of who has the right to supervise $\mathrm{PhD}$ candidates, including how this corresponds with academic titles.

7. All sources of funding - university-level, national-level, project-linked funding, other funding opportunities — with full details and relevant links.

8. Length of requirement for full fees.

9. Opportunities for teaching assistant work.

Given that there are noticeable differences between departments or faculties (such as is often the case for English language requirements), making this clear could significantly reduce confusion.

Too much information in one place can be overwhelming, so careful consideration also needs to be given as to how and when this is provided. Another way of helping to reduce students' uncertainties would be for institutions to offer more 'online enquiry sessions' for PGR students. Students could be encouraged to submit queries in advance if they wish, and the event in itself could help legitimise for students their right to raise questions while simultaneously lowering their concerns that questions could in themselves reflect badly on them. In addition, such events could help address the unequal playing field for internal and external applicants (i.e. those already at the university and those applying from outside) that Mellors-Bourne et al. (2014) have identified.

\section{Communication management}

The two main areas of concern around communication were the timing and frequency of contact with the potential or future supervisor and difficulties in interpreting messages. It is useful here to consider how communication operates. Although human communication to a large extent exploits a language code (such as English, Chinese, or Korean), it is not feasible for everything to be conveyed explicitly in the code. As a result, people use two main sources of knowledge to construct meaning in interaction: linguistic knowledge (i.e. knowledge of the language code) and 'world' knowledge (i.e. experiential and theoretical knowledge of social processes, facts, concepts, and so on) (Spencer-Oatey \& Franklin, 2009; Kecskés, 2014). In 
communication between international applicants and university staff, both sources of knowledge can give rise to potential difficulties, for the following reasons:

- There is less shared background knowledge, so the interpretation of meaning becomes more dependent on explicit explanations/descriptions.

- Staff may be unaware of the extent to which they are assuming shared background with applicants when wording their communications with them.

- Staff may be unaware of the extent to which the wording of their communications with applicants is implicit rather than explicit.

When these situations prevail, such 'meaning construction' as explained above can be particularly problematic. As a result, mismatches may occur in the messages that people think have been communicated, or alternatively, one or both parties may be confused and may request clarification. We therefore recommend that universities review their information and messaging from the following angles:

10. How explicitly is the message conveyed?

11. What background information is needed to understand the message?

12. What guidelines are provided regarding contacting a supervisor?

In fact, the clearer and the more substantial the information provided for the application steps, the greater the background knowledge prospective applicants will have and the easier it will be for them to interpret the underlying meaning of messages. It would also be useful for staff to receive some training in intercultural communication, using examples such as Q7 and Q8 to help them understand the importance of considering the recipient's level of background knowledge of application processes when structuring their messages. A specially designed e-course could be particularly helpful for this.

There were also concerns about maintaining a positive impression and how asking certain questions might affect the (potential) supervisor's evaluation of them (e.g. Q9) (see Kim and Spencer-Oatey, 2020, for further details on this aspect).

\section{Limitations and concluding comments}

Our study has only focused on Korean students interested in studying for a $\mathrm{PhD}$ in the UK. As such, we cannot be sure whether PGR students of other nationalities are likely to face similar challenges. Nevertheless, since the same fundamental intercultural issues applydifferent educational systems and different background knowledge-we believe that $\mathrm{PhD}$ applicants from other countries are likely to have similar or comparable queries. We maintain, therefore, that our findings not only relevant for Korean applicants but also relevant to PGR students from other countries, at the very least for reflection and checking.

The principle of gaining insights from social media websites to facilitate the application process may also be relevant for other levels of study. While the application process is more nationally controlled and less negotiable for undergraduate students (whatever their background), with fewer associated 'application steps', such students may still have uncertainties that emerge from such data and the universities are unaware of. Master's students are likely to have even more such uncertainties than undergraduate applicants, and in fact 
within our dataset (not reported here), they raised quite a wide range of questions, several of which were similar to those reported here for PhD students.

So, we strongly recommend that universities establish projects to monitor online virtual communities in different countries, similar in principle to the two forums examined in this study. This will enable them to identify the uncertainties that prospective students are experiencing and to gain more insights into the information that is missing from their websites or application handling procedures. A very useful outcome could be set of FAQs that are based on the questions raised in such forums. One option could be to recruit alumni to help with this. Alternatively, university networks or national bodies could support such initiatives.

As reported above, Mellors-Bourne et al. (2014) recommend gathering more data on PGR applications from PGR students, including adding relevant questions to key national surveys. Social media data such as reported in this study could help inform the design of the questions in such surveys, in terms of both focus and detailed wording. For example, the QS survey International Student Survey (Berka \& Strods, 2020) refers only to 'university staff' and does not distinguish between academic and admissions staff. Yet this distinction is extremely important for PGR applicants as it relates closely to uncertainties around who has the right to make application decisions. Such more specific options, therefore, need to be incorporated in future survey designs.

Consideration also needs to be given to national-level websites offering information on recruitment and study in the UK (e.g. UKCISA's webpages). At present only one such site (Prospects) provides any meaningful detailed information on PGR applications, and others could usefully consider their own role in relation to PGRs. Since HEIs almost certainly have different postgraduate application procedures at a detailed level, it could be helpful for national-level webpages to make that clear, to help reduce the kind of confusion that can occur when some universities encourage prior contact with a potential supervisor and others do not.

Given the UK government's R\&D targets for 2027, the recruitment challenges resulting from Brexit and the Covid-19 pandemic, as well as the shifting power dynamics internationally (e.g. the trend for China to become a major regional hub for international students, especially for those from other Asian countries, as Bothwell, 2020 argues), it is clearly important for universities in the UK and beyond to maximise their PGR recruitment potential. Now could therefore be a crucial time to draw on the insights revealed by our study, to review current practice, and to plan for the future by exploring comparable forums in other countries.

Acknowledgement We are grateful to Universities UK International (UUKi) and the UK Department for Business, Energy and Industrial Strategy (BIES) for a Rutherford Strategic International Fellowship in 2018 which allowed Kyung Hye Kim to carry out collaborative research in Warwick, UK, with Helen SpencerOatey, and to Shanghai Jiao Tong University and University of Warwick for their support. We also thank the anonymous reviewers for their helpful feedback on an earlier version of the article.

\section{Webpages}

Postgraduate Research Experience Survey (PRES): https://www.advance-he.ac.uk/reportspublications-and-resources/postgraduate-research-experience-survey-pres

Prospects: prospects.ac.uk/postgraduate-study/phd-study.

Steps to Postgraduate Study: postgradsteps.officeforstudents.org.uk.

Study UK: study-uk.britishcouncil.org. 
UK Council for International Student Affairs (UKCISA): https://www.ukcisa.org.uk/

University of Cambridge Postgraduate Application Process page: https://www.graduate. study.cam.ac.uk/application-process/what-happens-next (last accessed 6 July 2020).

University College London 'Guidance on how to contact potential supervisors' page: https ://www.ucl.ac.uk/prospective-students/graduate/sites/prospective-students_graduate/files/ potential-supervisor.pdf (last accessed 6 July 2020).

University of Manchester 'Choosing a supervisor' page: https://www.manchester.ac.uk/ study/postgraduate-research/admissions/how-to-apply/choose-supervisor/ (last accessed 6 July 2020).

University of Manchester 'Funding' page: https://www.manchester.ac.uk/study/postg raduate-research/funding/ (last accessed 6 July 2020).

University of Oxford Application Guide page: http://www.ox.ac.uk/admissions/graduate/ applying-to-oxford/application-guide (last accessed 6 July 2020).

University of Oxford Decision timeline page: https://www.ox.ac.uk/admissions/graduate/ after-you-apply/decision-timeline?wssl=1 (last accessed 6 July 2020).

\section{References}

Archer, W. (2016). International postgraduate research students: the UK's competitive advantage. London: The UK HE International Unit. Retrieved from https://www.universitiesuk.ac.uk/International/news/ Pages/uk-competitive-advantage.aspx [30 September 2020].

Berka, A \& Strods, C. (2020) International Student Survey, electronic dataset, Quacquarelli Symonds, viewed 5 October 2020. http://qs.com.

Bolat, E., \& O'Sullivan, H. (2017). Radicalising the marketing of higher education: learning from studentgenerated social media data. Journal of Marketing Management, 33(9-10), 742-763. https://doi.org/ 10.1080/0267257X.2017.1328458.

Bothwell, E. (2020). China told to reform education model to become global student hub. https://www. timeshighereducation.com/news/china-told-reform-education-model-become-global-student-hub. Accessed 19 August 2020.

Cheong, S., \& Song, A. (2010). 대학 - 기업, ‘해외파 박사' 선호가 문제 [Universities and Companies' preference for recruiting doctoral candidates who have graduated from overseas universities is problematic], University News Network, http://news.unn.net/news/articleView.html?idxno=62668. Accessed 3 November 2020.

Cortazzi, M., \& Jin, L. (2002). Cultures of learning, the social construction of educational identities. In D. C. S. Li (Ed.), Discourses in Search of Members: In Honor of Ron Scollon (pp. 49-78). New York: University Press of America.

Gai, L., Xu, C., \& Pelton, L. E. (2016). A netnographic analysis of prospective international students' decision-making process: implications for institutional branding of American universities in the emerging markets. Journal of Marketing for Higher Education, 26(2), 181-198.

Galan, M., Lawley, M., \& Clements, M. (2015). Social media's use in postgraduate students' decision-making journey: an exploratory study. Marketing for Higher Education, 25(2), 287-312. https://doi.org/10. 1080/08841241.2015.1083512.

HESA. (2020). Higher education student statistics: UK, 2018/19. https://www.hesa.ac.uk/news/16-01-2020/ sb255-higher-education-student-statistics/location. Accessed 19 August 2020.

Hsieh, H.-F., \& Shannon, S. E. (2005). Three approaches to qualitative content analysis. Qualitative Health Research, 15(9), 1277-1288. https://doi.org/10.1177/1049732305276687

Kecskés, I. (2014). Intercultural Pragmatics. Oxford: Oxford University Press.

Kim, K. H., \& Spencer-Oatey, H. (2020). Goals, uncertainties and contextual assessments: Korean students' concerns about relating to UK academics. Pragmatics. https://doi.org/10.1075/prag.20004.kim.

Kim, S.-C. (2020). [아침을 열며] 국내 대학원이 외면받는 이유 [[Opening Morning] Reasons why Korean local graduate schools are avoided], https:/www.hankookilbo.com/News/Read/2020012311 01774318 Accessed 3 November 2020. 
The Korean Education Centre UK. (2019). 2019년 주재국 내 한국인 유학생 현황 [Status of Korean international students in the host country in 2019] http://www.koreaneducentreinuk.org/wp-content/ uploads/2019/05/2019\%EB\%85\%84-\%EC\% 98\%81\%EA\%B5\%AD-\%EB\%82\%B4-\%ED\%95\%9C\% EA\%B5\%AD\%EC\%9D\%B8-\%EC\%9C\%A0\%ED\%95\%99\%EC\%83\%9D-\%ED\%98\%84\%ED\%99\%A9. pdf Accessed 3 November 2020.

Mellors-Bourne, R., Metcalfe, J., Pearce, E., \& Hooley, T. (2014). Understanding the recruitment and selection of postgraduate researchers by English higher education institutions. Report to HEFCE by CRAC/ Vitae and iCeGS. Available at http://www.ukcge.ac.uk/Search/Default.aspx?q=Understanding+the+ recruitment+and+selection+of+postgraduate+researchers+by+English+higher+education+institutio ns [Retrieved 30 September 2020].

Montgomery, C. (2009). A decade of internationalisation: has it influenced students' views of cross-cultural group work at university? Journal of Studies in International Education, 13(2), 256-270. https://doi. org/10.1177/1028315308329790

Mowen, J. C., \& Minor, M. (2006). Consumer behaviour: a framework. Mason, OH: Thomson.

OECD. (2018). Education at a Glance 2018: OECD Indicators, https://www.oecd-ilibrary.org/education/ education-at-a-glance-2018_eag-2018-en Accessed 19 August 2020.

Royo-Vela, M., \& Hünermund, U. (2016). Effects of inbound marketing communications on HEIs' brand equity: the mediating role of the student's decision-making process. An exploratory research. Journal of Marketing for Higher Education, 26(2), 143-167. https://www.tandfonline.com/doi/abs/10.1080/ 08841241.2016.1233165? journalCode $=$ wmhe20

Spencer-Oatey, H., \& Dauber, D. (2017). The gains and pains of mixed national group work at university. Journal of Multilingual and Multicultural Development, 38(3), 219-236.

Spencer-Oatey, H., \& Dauber, D. (2019a). What is integration and why is it important for internationalisation? A multidisciplinary review. Journal of Studies in International Education, 29(5), 515-534.

Spencer-Oatey, H., \& Dauber, D. (2019b). Internationalisation and student diversity: opportunities for personal growth or numbers-only targets? Higher Education, 78, 1035-1058.

Spencer-Oatey, H., \& Franklin, P. (2009). Intercultural interaction: a multidisciplinary approach to intercultural communication. Basingstoke: Palgrave Macmillan.

Statistica. (2020). Internet usage in South Korea - Statistics \& Facts https://www.statista.com/topics/2230/ internet-usage-in-south-korea/ [Accessed 4 November 2020].

Statistics Korea. (2020). 국내/외 박사학위 취득자 현황 [Current status of PhD graduates inside/ ouside Korea] Retrieved from http://www.index.go.kr/potal/main/EachDtlPageDetail.do?idx_cd= 1550 [Accessed 4 November 2020].

UK Council for Graduate Education (UKCGE). (2020). Industrial strategy: Postgraduate education's role in delivering the research and development target. UKCGE Resource: Policy Briefings. Retrieved from http://www.ukcge.ac.uk/article/policy-briefing-doctoral-researchers-rd-404.aspx\#_edn2 [Accessed 2 October 2020].

Zhou, Y. R., Knoke, D., \& Sakamoto, I. (2005). Rethinking silence in the classroom: Chinese students' experiences of sharing indigenous knowledge. International Journal of Inclusive Education, 9(3), 287-311.

Publisher's Note Springer Nature remains neutral with regard to jurisdictional claims in published maps and institutional affiliations. 